\title{
Nutrition in neurological disability in paediatrics: cerebral palsy
}

The case study has been adapted from the original case discussion at the South African Society for Parenteral and Enteral Nutrition (SASPEN) 2011 Congress held at Diep-in-die-Berg, Pretoria. A summarised discussion of the case follows.

\section{Introduction}

The learning objectives of the case study were:

- To discuss the growth monitoring of children with cerebral palsy (CP). Which growth charts should, or could, be used?

- To discuss the nutritional recommendations of infants and children with $\mathrm{CP}$.

- To discuss the possible drug-nutrient interactions and the nutrition-related side-effects of anticonvulsants.

- To discuss ethical considerations concerning the placement of gastrostomy tubes in infants and children with $\mathrm{CP}$.

\section{Case study}

The patient was a seven-month-old male, admitted to a tertiary hospital in South Africa, while his parents were visiting from a neighboring developing country with an immature healthcare system.

He was admitted with the following diagnoses:

- Bronchopneumonia

- Cerebral palsy (CP) with spastic diplegia: CP can be defined as a disorder of aberrant control of movement and posture, appearing early in life, secondary to a central nervous system lesion or dysfunction that is not the result of recognised progressive or degenerative brain disease. The diagnosis of $\mathrm{CP}$ always involves a motor deficit. "Spastic" describes the muscle tone that is increased in spastic diplegia usually, as opposed to hypotonia. "Diplegia" is motor impairment of both legs primarily, with limited involvement of the arms. ${ }^{2,3}$

- Epilepsy with breakthrough seizures

- Marasmus.
Upon admission, he was referred to the attending dietitian for nutrition care.

\section{Background}

The patient was born term, but due to a delayed labour process, suffered neurological damage during the birth. This caused seizures after the birth, and CP with spastic diplegia. He had a history of several previous admissions to hospital in his home country, as well as seizures and pneumonia.

Although his mother was retroviral disease (RVD) positive, the infant tested polymerase chain reaction (PCR) for RVD negative at six months of age. The father was also RVD positive, but neither he nor his wife were receiving antiretroviral (ARV) therapy. Both parents were unemployed.

Table I: Patient's anthropometric parameters

\begin{tabular}{|l|c|c|c|c|c|}
\multirow{2}{*}{$\begin{array}{c}\text { Admission } \\
\text { (age 7 months) }\end{array}$} & \multicolumn{4}{|c|}{} \\
\cline { 2 - 6 } \multicolumn{2}{c|}{ Way 1 } & Day 7 & Day 13 & Day 20 \\
\hline Weight & $3250 \mathrm{~g}$ & $3800 \mathrm{~g}$ & $4300 \mathrm{~g}$ & $5130 \mathrm{~g}$ & $4140 \mathrm{~g}$ \\
\hline Length & & $53 \mathrm{~cm}$ & & & \\
\hline
\end{tabular}

\section{Causes of the apparent discrepancy in the patient's weight between days 13 and 20}

The weight discrepancy between day 13 and 20 could not be explained as easily as that between days 1 and 7 . It is highly likely that there was an element of dehydration upon admission, and that this was subsequently corrected. There could be many reasons for the discrepancy between days 13 and 20, including inaccurate weighing methods, e.g. with or without clothes and splints, different scales, or fluid overload or retention. Unfortunately, no albumin or 
C-reactive protein (CRP) levels were available to correctly determine the cause. However, a review of the progress notes and nutrition prescription showed high fluid allowances around day $7(177 \mathrm{ml} / \mathrm{kg} /$ day) at times, in order to meet the nutritional requirements. On day 13 , the fluid intake was reduced to $129 \mathrm{ml} / \mathrm{kg} /$ day, due to feeding problems. However, this could be a skewed view of $\mathrm{ml}$ fluid $/ \mathrm{kg} / \mathrm{day}$, due to the apparent incorrect weight on day 13. This confirms the importance of correct weighing, in order to be able to calculate the nutrition requirements correctly.

\section{Growth charts to be used for growth monitoring in this population}

Growth monitoring of the $\mathrm{CP}$ population remains difficult and controversial, and different growth references exist. Evidence suggests that this population does not exhibit the same growth pattern as the general population, e.g. weight-for-age percentiles of children with $\mathrm{CP}$ are lower than those in the general population. ${ }^{4}$ This is especially true in children with more severe motor dysfunction. Poor growth, loosely defined, is associated with increased hospitalisation and school absences. Growth charts for children with quadriplegic $\mathrm{CP}$ were developed by Krick et $\mathrm{al}^{5}$ at the Krieger Kennedy Institute, and have been widely used, as there were no others available. However, the sample size was small, and was limited to a specific group of CP patients.

Evidence-based thresholds for low weight, and estimates of associated increases in mortality risk, have been illustrated using new clinical growth charts for children with $\mathrm{CP}$, stratified according to gender and gross-motor function classification system levels. These were developed by Day et al, ${ }^{4}$ based on more than 141000 measurements of almost 25000 patients receiving services from the California Department of Developmental Services. However, these could not be used in the case of the patient under discussion, as they are only available for patients who are two years and older Wittenbrook ${ }^{6}$ recommends that the Centres for Disease Control and Prevention growth charts are used to monitor children with $\mathrm{CP}$, even when measurements are consistently below the fifth percentile. The goal is to have appropriate growth velocity, and for the child to follow his or her growth curve. Disease-specific growth charts are available

Table II: Blood counts and biochemistry results for selected days during admission to hospital

\begin{tabular}{|l|c|c|c|c|}
\hline & Day 1 & Day 4 & Day 15 & Day 25 \\
\hline White cell count & 31.2 high & 21.47 high & 4.22 & 7.73 \\
\hline Haemoglobin & 11.5 & 10.8 & 9.9 low & 10.9 \\
\hline Hct & 0.33 & 0.332 & 0.30 & 0.32 \\
\hline Mean corpuscular volume & 84.3 & 85.1 & 88.3 & 87.0 \\
\hline Sodium & 140 & 139 & 139 & 138 \\
\hline Potassium & 4.8 & 4.2 & 4.5 & 4.1 \\
\hline Chloride & 106 & 100 & 99 & 100 \\
\hline C0 2 & 20 low & 21 low & 27 & 23 low \\
\hline Urea & 2.2 low & 2.5 low & 2.7 low & 2.6 low \\
\hline Creatinine & 35 low & 32 low & 28 low & $<20$ low \\
\hline
\end{tabular}

to assess the "typical" growth related to the various syndromes, and could be used for our patient, but small sample sizes, age ranges, and lack of availability in acute care settings, limit their use. Close monitoring still remains the best practice as there are too few sufficiently powered studies to provide evidence-based references for CP children in the 0-2 years' age group. ${ }^{6,7}$ It is important to determine if a particular child maintains his or her individual growth velocity, irrespective of which growth charts are used.

Table II reflects blood counts and available biochemistry results for certain days of the patient's admission to hospital.

\section{Interpretation of the urea and creatinine results}

Creatinine is a product of muscle creatinine-phosphate metabolism, and its level parallels muscle mass. Urea is produced in the liver from protein degradation. ${ }^{8}$ In this case, the patient was diagnosed with marasmus which is characterised by muscle wasting, so the low urea and creatinine levels were not unexpected.

\section{Clinical signs}

Clinical signs included:

- Irritability and crying, but the patient was consolable

- Coughing

- Vomiting (one episode)

- Increased tone globally

- Increased reflexes globally

- Cervical lymphadenopathy.

\section{Clinical signs that should be of concern to the dietitian, and why}

Coughing and vomiting are taken to be evidence of swallowing dysfunction. This was confirmed by a video fluoroscopy. The vomiting prevented optimal intake by mouth.

Increased tone and reflexes: Increased energy requirements, as compared to children with severe motor dysfunction. ${ }^{7}$

\section{Diet history}

The baby was fed with a breast milk substitute. Initially, he received two bottles of $200 \mathrm{ml}$ Nan $1^{\circledR}$ per day (eight scoops of powder). Introduction to solids was started at five months of age. When at home, he consumed Nestum ${ }^{\circledR}$ cereal and Purity ${ }^{\circledR}$ orally. His mother reported oral feeding difficulties.

\section{Factors that influence the nutrition requirements of infants with cerebral palsy}

\section{Mobility and muscle tone}

The level of gross motor function impairment will determine physical activity and muscle tone, and will influence energy requirements. For example, children with athetoid $\mathrm{CP}$ or hypertonia may have increased requirements, whereas children with hypotonia will have decreased requirements. ${ }^{7}$ 


\section{Dysphagia and feeding ability}

It is important to determine whether optimal intake by mouth is possible. $^{7}$

\section{Medications and their side-effects}

Medications to reduce hypertonia often reduce energy expenditure. Some antipsychotics lead to weight gain, due to appetite stimulation. ${ }^{6}$

\section{Bowel actions}

Dysmotility, hypotonia, medications, and non-ambulation contribute to constipation. ${ }^{6}$

\section{Pulmonary status}

Progressive fatigue towards the end of a meal may be an indication of silent aspiration and desaturation. ${ }^{9}$

\section{The protein and energy recommendations for infants with cerebral palsy}

\section{Energy}

Disability-specific standards for estimating energy needs in children with CP are available. However, they are often of limited use due to small sample size, limited studied age ranges, and the necessity for accurate stature measurement. Typical prediction equations can overestimate requirements by as much as $20 \%$, leading to an overweight individual. No two CP individuals are the same, and energy needs must be adjusted regularly, according to the current medical status. It is not uncommon to see a hypotonic, hypometabolic individual with CP maintain his or her weight with a very low energy intake. This poses another challenge to the dietitian as micronutrient requirements are then often not met. Supplementation with ageappropriate vitamin and mineral supplements is then indicated to meet at least the daily recommended intake (DRI). Individual requirements may be different, based on the current medical condition. ${ }^{6,7}$

\section{Protein}

The DRI is used to estimate protein requirements based on actual weight. ${ }^{6,7}$ Therefore, it is evident that once again, close and regular monitoring remains the best practice to assure optimal growth and development of the CP patient.

\section{Medication}

Medication includes Amikacin ${ }^{\circledR}$, Panado $^{\circledR}$, Epilim $^{\circledR}$, Rivotril ${ }^{\circledR}$, and Phenytoin. ${ }^{\circledR}$

\section{Medications that impact on enteral nutrition support and medical treatment: limiting their impact}

\section{Phenytoin}

When administered concurrently with food, phenytoin absorption may be reduced by up to $70 \%$, thus decreasing serum drug levels.
There are two possible ways that the impact can be limited:

- Hold back feeding for two hours before and after feeds, and flush the feeding tube with water after each dosing.

- If feeds cannot be held for the recommended times, the dose of phenytoin should be adjusted to assure the required therapeutic drug level. ${ }^{10}$

\section{Micronutrients that should be of concern with the use of anticonvulsants}

\section{Folate and other B-vitamins}

Some anticonvulsants decrease s-levels of folate, Vitamin B12, biotin and thiamine. ${ }^{11}$ Furthermore, frequently prescribed anticonvulsant medications, such as valproic acid, phenytoin and carbamazepine, are associated with alterations in Vitamin D and calcium metabolism, and should be closely monitored. ${ }^{7}$

Table III summarises the progress notes of some members of the interdisciplinary healthcare team involved in the rehabilitation of the patient, i.e. the clinical dietitian, speech therapist and physiotherapist.

The patient continued to receive intensive rehabilitation therapy from the occupational, physical and speech therapists, while awaiting the barium swallow and a percutaneous endoscopic gastrostomy (PEG) placement. It was expected that the patient would be discharged after successful PEG placement, to return with his parents to his home country.

\section{Practical issues that might influence the long-term nutritional care of this patient}

Practical issues that might influence the long-term nutritional care of this patient include:

- Available care in his home country, if the PEG was inserted.

- Household food security, in view of his parents' lack of income.

- Long-term follow-up is the best practice in the absence of evidence-based guidelines. Regular follow-ups are recommended to ensure optimal growth and development. ${ }^{6,7,9,12}$

\section{Ethical considerations regarding placement of a gastrostomy tube in this patient}

Many studies have shown that inserting a PEG or gastrostomy tube improves the nutrition status of children with $\mathrm{CP}$ and concurrent feeding difficulties, as well as improving the quality of life of the caregiver. ${ }^{9}$ However, in this case, the dietitian was faced with an ethical dilemma of what to recommend. The availability of health care in the patient's home country was of great concern, as it was not known if the parents would be able to receive assistance in the event of problems with the feeding tube, e.g. infection or dislodgement. It was doubtful whether there would be sustainability of nutritional care, due to the household's food insecurity and the lack of family income. Long-term care of this patient was also problematic in view of the parents' RVD status. Who would ultimately care for this patient? Neither of the parents were on ARV therapy that would delay the diseases' progress. 
Table III: Progress while undergoing treatment in hospital

\begin{tabular}{|l|l|}
\hline Day & Progress note \\
\hline Day 3 & $\begin{array}{l}\text { Clinical nutrition: The feed was changed to } \mathrm{Nan} 2^{\circledR}, 80 \mathrm{ml} \mathrm{x} \\
8 \text { feeds per day (177 } \mathrm{ml} / \mathrm{kg} / \mathrm{day}, 120 \mathrm{kCal} / \mathrm{kg}, 4 \mathrm{~g} \text { protein/ } \\
\mathrm{kg} \text { ) and a pureé diet. } \\
\text { Occupational therapy. The child was unable to sit, roll, } \\
\text { grasp, maintain head control, or play. It was not possible to } \\
\text { arouse him. Splinting was recommended. } \\
\text { Physiotherapy: Physiotherapy was started with the } \\
\text { facilitation of midline and supported sitting. }\end{array}$ \\
\hline Day 4 & $\begin{array}{l}\text { Speech therapy: Gagging and coughing was observed } \\
\text { during feeding. The patient could not be fed orally safely, } \\
\text { and nasogastric feeding was recommended. }\end{array}$ \\
\hline Day 7 & $\begin{array}{l}\text { Clinical nutrition: The patient's weight was } 4.3 \mathrm{~kg} . \text { The Nan } \\
2^{\circledR} \text { was increased to } 95 \mathrm{ml} \mathrm{x} 8 \text { feeds per day }(177 \mathrm{ml} / \mathrm{kg} / \\
\text { day, } 120 \mathrm{kCal} / \mathrm{kg}, 3.9 \mathrm{~g} \text { protein } / \mathrm{kg} \text { ). The mother reported } \\
\text { one episode of vomiting after feeding. Her son passed soft } \\
\text { yellow stools. }\end{array}$
\end{tabular}

Days 8-12 Medical therapy and enteral nutrition support continued. Breakthrough seizures were noted. The patient was given a loading dose of phenytoin when the seizures occurred. This affected his consciousness levels.

Day 13 Clinical nutrition: The mother reported vomiting post feeding, and the presence of milk residue in the mouth. The feed volume was decreased to $85 \mathrm{ml} \times 8$ feeds per day, and supplemented with sunflower oil and modular carbohydrate and protein, to meet requirements $(129 \mathrm{ml} / \mathrm{kg} /$ day, 106 $\mathrm{kCal} / \mathrm{kg}, 3.7 \mathrm{~g}$ protein $/ \mathrm{kg}$ ).

Day 15 A consultant pediatrician suggested percutaneous endoscopic gastrostomy placement, with no postanaesthetic ventilation. No objective feeding assessment, e.g. video fluoroscopy, had been carried out. The possibility of percutaneous endoscopic gastrostomy was discussed with the mother.

Day 20 Clinical nutrition: The patient's weight was $4.1 \mathrm{~kg}$. The feeds were increased to $\mathrm{Nan} 2^{\circledR}, 95 \mathrm{ml} \times 8$ feeds per day (supplemented, $186 \mathrm{ml} / \mathrm{kg} /$ day, $140 \mathrm{kCal} / \mathrm{kg}, 4 \mathrm{~g}$ protein/ $\mathrm{kg})$.

Day 21 Speech therapy: Video fluoroscopy was carried out. Severe tonic bite, severe penetration and residue in the valleculae and pyriform sinus were noted when feeding thin or thickened liquids. The patient was unable to cough, or clear a paste consistency. The need for gastrostomy was confirmed. The patient was referred to paediatric surgery for percutanuous endoscopic gastrostomy placement. The paediatric surgeons required a contrast swallow study to rule out reflux and the necessity for a simultaneous Nissan fundoplication

Day 22 - 30 On various occasions, the mother was counselled regarding the percutaneous endoscopic gastrostomy placement and feeding post placement. The patient was referred for a visual assessment, and was found to be blind.

The core principles of ethics in clinical practice are beneficence (doing good), non-maleficence (do no harm), respect for autonomy (the right to self-determination) and justice (impartial, fair and just treatment). ${ }^{13}$ The South African dietitian registered with the Health Professions Council of South Africa (HPCSA) is bound to these principles as per the Guidelines for good practice in healthcare professions: general ethical guidelines for healthcare professions. ${ }^{14}$
In this document, the healthcare professional is given guidance in ethical reasoning that proceeds according to four steps:

- Formulating the problem.

- Gathering information.

- Considering the options.

- Making a moral assessment.

While following these steps, the dietitian should consult authoritative sources for guidance. One such source may be the Academy of Nutrition and Dietetics' (formerly the American Dietetic Association) position on ethical and legal issues in nutrition, hydration and feeding. In summary, it states that healthcare team members, including the registered dietitian, must set treatment goals that are patientcentered and handled individually, and must respect the values and decision of the patient, or in this case, that of his caregivers. ${ }^{15}$ In the South African context, the final decision rests with the medical doctor and caregiver, and the dietitian is only a consultant in the process, making recommendations for nutritional care, but must remain an advocate for the patient and his family.

\section{References}

1. Ashwal S, Russman BS, Blasco PA, et al. Practice parameter: diagnostic assessment of the child with cerebral palsy: report of the Quality Standards Subcommittee of the American Academy of Neurology and the Practice Committee of the Child Neurology Society. Neurology. 2004;62(6):851-863

2. Rosenbaum P. Cerebral palsy: what parents and doctors want to know. BMJ. 2003;326(7396):970 -974

3. Liptak GS, Murphy NA, Council on Children With Disabilities. Providing a primary care medical home for children and youth with cerebral palsy. Pediatrics. 2011;128(5):e1321-e1329 [homepage on the Internet]. Available from: http://pediatrics.aappublications.org/ content/128/5/e1321.full.pdf+html

4. Day S, Strauss DJ, Vachon PJ, et al. Growth patterns in a population of children and adolescents with cerebral palsy. Dev Med Child Neurol. 2007;49(3):167-171.

5. Krick J, Murphy-Miller P, Zeger S, Wright E. Pattern of growth in children with cerebral palsy. $J$ Am Diet Assoc. 1996;96(7):680-685

6. Wittenbrook W. Nutritional assessment and intervention in cerebral palsy. Practical Gastroenterology. 2011;16:21-32

7. Wolff J, Sinesi M. Enteral management of children with neurological disease. Support Line. 2011;33(5):3-10

8. Himes R, Shulman R. Use of laboratory measurements in nutritional assessment. In: Koletzko B, editor. Pediatric nutrition in practice. Basel: Karger; 2008.

9. Marchand V, Canadian Paediatric Society. Nutrition and Gastroenterology Committee. Nutrition in neurologically impaired children. Paediatr Child Health. 2009;14(6):395-401.

10. Williams NT. Medication administration through enteral feeding tubes. Am J Health Syst Pharm. 2008;65(24):2347-2357 [homepage on the Internet]. Available from: http://www.medscape. com/viewarticle/585397

11. The importance of nutrition for the person with epilepsy. Nutrition Information Centre Stellenbosch University (NICUS) [homepage on the Internet]. c2011. Available from: http:// www.sun.ac.za/nicus

12. Mascarenhas MR, Meyers R, Konek S, et al. Outpatient nutrition management of the neurologically impaired child. Nutr Clin Pract. 2008;23(6):597-607

13. Moodley K. Ethics in clinical practice: an overview. CME Journal. 2006;24(1):30-34

14. Guidelines for good practice in healthcare professions: general ethical guidelines for health care professions. Health Professions Council of South Africa. 2008 c2012. [homepage on the Internet]. Available from: http://www.hpcsa.co.za/downloads/conduct_ethics/rules/generic_ ethical_rules/booklet_ 1 guidelines good_prac.pdf

15. O'SullivanMaillet J Position of the American Dietetic Association: Ethical and legal issues in nutrition, hydration, and feeding. J Am Diet Assoc. 2008;108(5):873-882. 